\title{
POĹtICAS PÚBLICAS E REGULAÇÃo dA EDUCAÇÃo: TEMAS EM DEBATE ${ }^{1}$
}

O livro Políticas públicas e regulação da educação: temas em debate, lançado pela Editora Mercado de letras - Campinas, SP é um conjunto de trabalhos de pesquisadores do Brasil e de outros países, a saber: México e Portugal. Tem como foco principal as opções políticas e as práticas de regulação operadas no setor, refletindo e compartilhando a análise acerca das questões e dilemas que atravessam as políticas educacionais contemporâneas. A obra organizada pelos Doutores Elton Luiz Nardi (Unoesc), Maria de Lourdes Pinto de Almeida (Unoesc/Unicamp), e Isabel Maria Torres Carvalho Viana (Universidade do Minho/Portugal)), reúne nove capítulos organizados em duas partes, sendo a primeira reservada para o enfoque das "Tendências, agendas e imperativos da regulação da educação" e a segunda parte, para os debates das "políticas e regulação da educação no Brasil".

A temática de abertura do livro, Regulação da educação: políticas, dilemas e perspectivas, escrita pelos organizadores dessa obra, além de trazer uma breve síntese de cada capítulo, os autores discorrem ao longo do texto sobre algumas das múltiplas questões que implicam nas atuais políticas públicas, contextualizando e interligando diretamente com a nova agenda global e os "movimentos políticos, sociais e culturais" que incidem na prática da regulação educacional (NARDI; ALMEIDA; VIANA, 2015, p. 9). Em sua direção alertam para a emergência dos novos modelos de regulação que, alicerçados na nova gestão pública, no Estado avaliador e na lógica de quase-mercado, tendem a assumir novos delineamentos. Considerando-se essa nova forma de dominação, a ela segue atrelado o "[...] âmbito curricular, o da formação dos professores e a dimensão institucional da educação, crescentemente submetida ao signo da eficiência e da lógica de mercado que marcam, indelevelmente, o tempo presente" (NARDI; ALMEIDA; VIANA, 2015, p. 9).

No primeiro capítulo, Currículo nacional português e municipalização da educação: um modelo de mercantilização do cidadão de amanhã? Isabel Maria Torre Carvalho Viana (Universidade do Minho/Portugal) aponta as dimensões econômicas como condicionantes à vida individual e coletiva, restringindo o poder do cidadão no exercício da cidadania. Em reflexo, a escola passa a ser "racionalizada" para fins de atender e responder à lógica econômica, podendo ser comparada como "unidade de gestão comercial" (VIANA, 2015, p. 24). Problematiza as consequências desse contexto, para a municipalização da educação em Portugal, associando-a com argumentos da descentralização ao exercício da autonomia, já

\footnotetext{
${ }^{1}$ NARDI, L. E.; ALMEIDA, P. L. M.; VIANA, C. T.M. I. (Org.) Políticas públicas e regulação da educação: Temas em debate. Campinas, SP: Mercado de Letras, 2015.
} 
sinalizando a importância da consciência curricular para os desafios e transformações sociais desse processo, para o cidadão de amanhã.

No segundo capítulo, Elton Luiz Nardi (Unoesc) propõe um debate sobre a Autonomia da escola e regulação da qualidade: (pro) posições da CEPAL para políticas de gestão da educação na América Latina, realizando uma análise das proposições e posições assumidas pela Cepal, que considera que a educação deve ser "propulsora de novas mentalidades e novas práticas" (NARDI, 2015, p. 57). Para tal, defende que as políticas devem estar relacionadas com a educação, conhecimento e desenvolvimento. Nesse contexto, a educação passa a assumir sua responsabilidade diante das necessidades da produção e do consumo. Considerando que tal processo de gestão é flexível e descentralizador, Nardi aborda as questões da autonomia da escola pública e a regulação da qualidade da educação dos últimos tempos, analisando documentos publicados na década de 1990 que trazem elementos pertinentes a temática, tal como Transformación produtiva com equidade: la tarea prioritária del desarrollo de América Latina y el Caribe en los años noventa (1990) e o Inverstir mejor para investir más: Financiamento y Gestión de la Educación em América Latina y el Caribe (2015).

Jaime Morales Vásquez (Universidad de Colima), no terceiro capítulo, "Making the numbers" las políticas de evaluación de la productividad y su relación con las malas conductas y conductas cuestionables en las práticas académicas y científicas, argumenta sobre a possível relação das políticas de avaliação, os incentivos de produtividade acadêmica e a contínua expansão das más formas de agir diante das práticas acadêmicas e científicas. Entre tais práticas, estão a falsificação e o plágio, ou aquelas inclusas nas rotinas cotidianas acadêmicas. Descreve ainda a responsabilidade do mundo acadêmico perante esse comportamento que, segundo o autor, é geralmente culpabilizado pelos fatores externos, tal como a pressão para publicar, a concorrência e o próprio sistema.

O quarto capítulo escrito por Sara Aliria Jiménez García (Universidad de Colima), Nociones de identidad profesional en el SNI y en el PRODEP en México, ¿reduccionismo del trabajo académico y de la participación en las universidades? descreve as noções de identidades profissionais dos acadêmicos diante dos regulamentos do SNI (Sistema Nacional de Investigadores), CONACYT (2012 Y 2014) e do perfil PRODERP (Programa para el Desarrollo Profesional Docente). García aponta insuficiência de diálogo desses organismos para compreender a realidade das instituições de ensino superior, e sinaliza a necessidade de revisão das noções que fazem parte da avaliação educacional da realidade no México, a fim de entender as estratégias administrativas que têm seu peso nas práticas e costumes das ações do governo e das universidades.

Maria de Lourdes Pinto de Almeida (Unoesc/Unicamp), e Enrique Martinez Larrechea (UBA/UNR) discorrem, no quinto capítulo, sobre as Políticas y educación en América Latina: Estado evaluador y evaluación de desempeños educativos. No contexto das transformações iniciadas na década de 1980 e diante da redefinição do papel do Estado, tida 
como Estado-avaliador, preocupando-se com os indicadores de qualidade, a educação e a escola passam a ser responsabilizadas pelos processos educativos, tendo que, dessa forma, mostrar os resultados do seu desempenho. Segundo os autores, o Estado avaliador, sem dar vez e voz às questões de ordem social e pedagógicas, leva-nos a assinalar a necessidade da construção da relação entre as políticas e a avaliação numa perspectiva mais democrática, no sentido da escola ser repensada para a transformação.

Marilda Pasqual Scheneider (UNOESC) finaliza a primeira parte da obra com o texto Marcos conceituais do Preal para uma política de accountability educacional nos países da América Latina e Caribe. Segundo a autora, no final da década de 1980 o uso do termo accountability tornou-se mais frequente devido às mudanças na estrutura da política administrativa, que trouxe consigo questões como a prestação de contas e a transparência. Mesmo com a maior frequência do termo, sua compreensão e utilização ainda consiste num desafio, pois a definição do termo é polissêmica. No campo educacional, seja de âmbito micro ou macro, a accountability está ligada diretamente às questões de participação e transparência. A autora discorre ao longo do texto sobre as concepções de accountability defendidas pelo Programa de Promoción de la Reforma Educativa en América Latina y el Caribe (Preal), em face a educação pública, tendo em vista a implementação de uma política de accountability educacional nos países latino-americanos, considerando o seu viés de interesse e a quem ela responde.

Abrindo a segunda parte da obra, Afrânio Mendes Catani (USP), Mário Luiz Neves de Azevedo (UEM) e Ana Paula Hey (USP), escrevem o capítulo sete, Da autonomia do trabalho intelectual nas políticas públicas de educação superior no Brasil: Analistas, intelectuais, dirigentes e policymakers, com o objetivo de trazer uma análise da autonomia do trabalho intelectual diante do domínio das políticas públicas de educação superior. De acordo com os autores, cada época compõe uma geração diferente de intelectuais, cada qual com seus interesses, métodos e objetivos que vão em direção ao seu campo social específico, tendo como referência o grupo do qual fazem parte ou que lhe é de proximidade. Com base na teoria gramsciana, descrevem o papel do intelectual como promovedor da cultural e da ideologia frente a organizações tais como a economia, a política e a cultura. Dessa forma, os intelectuais, sejam eles orgânicos ou tradicionais, ao contrário dos Policymaker, que produzem com autoridade suas influências, são considerados analistas das políticas públicas, que segundo Bourdieu devem ser atores independentes na sociedade e não meros sacerdotes que reproduzem o que lhes é imposto.

No capítulo oito, intitulado Base nacional comum curricular para a educação básica: propostas em disputa, Leda Scheibe (UNOESC/UFSC), diante das políticas públicas no Brasil e a necessidade de uma base comum nacional para o currículo - como anunciou o MEC - diz que diferentes propostas vêm sendo apresentadas, tais como a posição de que os currículos devem ser produzidos pelos sistemas de ensino e escolas tendo suas características locais. Scheibe, para esse debate, levanta dois pontos, um sendo da identificação dos elementos culturais que precisam ser assimilados entre os estudantes, e outro que diz respeito

\begin{tabular}{l|l|l|l|l|l|l} 
(C) Rev. Inter. Educ. Sup. & Campinas, SP & v.2 & n.3 & p.591-594 & set./dez. 2016 & ISSN 2446-9424
\end{tabular}


às formas de organização dos trabalhos educativos sendo pressupostos para reflexão do tema analisado. A autora argumenta que é necessário "tomar especificidade do papel da escola como referência central para a organização curricular", no sentido da pertinência de conhecimentos necessários para o "projeto de humanização e democratização" (SCHEIBE, 2015, p. 202). Para tal, discute a relação entre as reformas e as políticas educacionais e curriculares, em interfaces da formação docente.

Neusa Chaves Batista (UFRGS), Cleusa Conceição Terres Schuch (UFRGS), e Jaqueline Marcela Villafuerte Bittencourt (UFRGS), escrevem o último texto, Monitoramento de políticas públicas educacionais no Brasil: análise da política nacional do $P A R$. No decorrer do trabalho, as autoras apresentam os resultados de uma pesquisa de monitoramento e análise institucional da Política Nacional de Ações Articuladas (PAR) tendo como cerne a qualidade da educação básica no Brasil. Para a análise e o acompanhamento realizado nos municípios gaúchos foram organizados quatro blocos a saber: " gestão educacional; formação de professores e dos profissionais de serviços e apoio escolares; das práticas pedagógicas e avaliação; da infraestrutura física e recursos pedagógicos" (BATISTA, et al, 2015, p. 216). Entretanto, as autoras deram ênfase à dimensão da gestão educacional no sentido do fortalecimento dos sistemas municipais de ensino e dos conselhos escolares, considerando os princípios da gestão democrática, para a qual concebem a necessidade de maior atenção.

No Posfácio, Enseñarle todo a todos o la hegemonía encubierta, escrito por Enrique Del Percio (UBA/UNR) e Maria Mercedes Palumbo (UBA), os autores partem da frase citada por Comenius "Ensinar tudo a todos", expressado no seu Didactica Magna, significando um gesto democratizante. Os autores refletem sobre três pontos que desafiam o sistema educativo, um deles seria o papel do educador como produtor do conhecimento, outro o aluno e sua relação com o processo da produção do conhecimento e, por fim, a implicação de ensinar tudo a todos. O eixo que perpassa essas dimensões está ligado diretamente aos sujeitos envolvidos, ao ato educativo e à construção do saber, dessa forma, a capacidade de "ensinar tudo a todos" está a par da possibilidade de "todo conhecimento".

A obra Políticas públicas e regulação da educação: temas em debate, proporciona ao leitor conhecimento vasto acerca da pluridimensionalidade do tema avaliação da educação, contextualizado ao longo do livro, por meio de relações com o Estado, o processo de mudanças das políticas públicas e as realidades nas quais estão imbricadas. Além disso, aborda as questões do ato educativo e o processo de construção do saber, sendo que esse não é justificativa da realidade, possibilitando-nos ver e questionar as formas e os mecanismos que são estabelecidos para a educação. Dessa maneira, podemos dizer que com a leitura, será possível conhecer algumas das múltiplas questões das políticas públicas contemporâneas, que se moldam às questões da nova agenda global. 